\title{
In-flight absolute calibration of the CBERS-2 CCD sensor data
}

\author{
FLÁVIO J. PONZONI ${ }^{1}$, JURANDIR ZULLO JUNIOR ${ }^{2}$ and RUBENS A.C. LAMPARELLI ${ }^{2}$ \\ ${ }^{1}$ Instituto Nacional de Pesquisas Espaciais, Divisão de Sensoriamento Remoto, \\ Avenida dos Astronautas 1758, 12227-010 São José dos Campos, SP, Brasil \\ ${ }^{2}$ Universidade Estadual de Campinas, Centro de Pesquisas Meteorológicas e Climáticas Aplicadas à Agricultura, \\ Cidade Universitária “Zeferino Vaz”, 13083-970 Campinas, SP, Brasil.
}

Manuscript received on May 25, 2006; accepted for publication on July 7, 2007; presented by ALCIDES N. SIAL

\begin{abstract}
Since the first images of the sensors onboard of CBERS-2 (China-Brazil Earth Resources Satellite) satellite were made available by the National Institute for Space Research (INPE), users have asked information about the conversion of image digital numbers to physical data (radiance or reflectance). This paper describes the main steps that were carried out to calculate the in-flight absolute calibration coefficients for CBERS-2 CCD level 2 (radiometric and geometric correction) images considering the reflectance-based method. Remarks about the preliminary evaluation of these coefficients application are also presented.
\end{abstract}

Key words: absolute calibration, CBERS-2, CCD, reflectance.

\section{INTRODUCTION}

Brazil and China have performed an important joint space program that includes the development of remote sensing satellites. The most important of them is the China-Brazil Earth Resources Satellite (CBERS).

The first satellite developed (CBERS-1) was launched on October $14^{\text {th }} 1999$ with great success by the Chinese Long March 4B launcher from the Taiyuan Satellite Launch Center in China. Its orbit was Heliossynchronous at a $778 \mathrm{~km}$ altitude and it performed about 14 revolutions a day obtaining a complete coverage of the Earth in 26 days. The second satellite (CBERS-2) was launched successfully from the same launch center on October $21^{\text {st }} 2003$, which carries the identical payload as CBERS-1.

The unique characteristics of CBERS-1 and 2 are their multi-sensor payloads with different spatial resolutions and image collecting frequencies. These features were specially designed to resolve the broad range of

Corrrespondence to: Flávio Jorge Ponzoni

E-mail: flavio@dsr.inpe.br space and time scales involved in Brazilian and Chinese ecosystems. CBERS has three on-board sensors: the WFI (Wide Field Imager), High Resolution CCD Camera (CCD), and the Infrared Multispectral Scanner (IRMSS). The spectral coverage and the swath width of these sensors are summarized in the Table I.

The CCD (High Resolution CCD Camera) collects $113 \mathrm{~km}$ wide images strip with $20 \mathrm{~m}$ spatial resolution. Since this camera has a sideways pointing capability of \pm 32 degrees, it is capable of taking stereoscopic images of a certain region. In addition, any phenomenon detected by the WFI may be "zoomed in" by the oblique view of the CCD camera with a maximum time lag of 3 days. The two spectral bands of the WFI are also present in the CCD camera that allows complementary data from two sensors with different spatial resolutions.

The CBERS-1 images were not used by the remote sensing communities of both countries, since improvements had to be done in data reception and processing to guarantee minimum quality (radiometric and geometric terms) to the images. When CBERS-2 was launched 
TABLE I

Spectral coverage of the CBERS-2 sensors.

\begin{tabular}{c|l|l|l}
\hline Parameter & \multicolumn{1}{|c|}{ CCD } & \multicolumn{1}{c}{ IRMSS } & \multicolumn{1}{c}{ WFI } \\
\hline & $0.51-0.73(\mathrm{PAN})$ & $0.50-1.10$ (PAN) & $0.63-0.69$ \\
& $0.45-0.52$ & $1.55-1.75$ (SWIR) & $0.76-0.90$ \\
Spectral bands $(\mu \mathrm{m})$ & $0.52-0.59$ & $2.08-2.35$ (SWIR) & \\
& $0.63-0.69$ & $10.4-12.5(\mathrm{TIR})$ & \\
& $0.77-0.89$ & & \\
\hline Spatial resolution & $20 \mathrm{~m}$ & $80 \mathrm{~m}(\mathrm{PAN} \&$ SWIR) & $260 \mathrm{~m}$ \\
& & $160 \mathrm{~m}(\mathrm{TIR})$ & \\
\hline Swath width (FOV) & $113 \mathrm{~km}\left(8.32^{\circ}\right)$ & $120 \mathrm{~km}\left(8.78^{\circ}\right)$ & $885 \mathrm{~km}\left(60^{\circ}\right)$ \\
\hline Temporal resolution & 26 days & 26 days & $3-5$ days \\
\hline
\end{tabular}

in 2003, several improvements had been performed in ground stations and image processing algorithms and the new images from CBERS-2 were distributed in China and in Brazil.

The success of any remote sensing program is directly related to the knowledge of both spectral and radiometric characteristics of the sensor from which the data will be available (Thome et al. 2004). A good example of that is the Landsat 5 Thematic Mapper (TM) sensor, whose radiometric characteristics have been evaluated and updated continuously over the its lifetime (Slater et al. 1987, Thome et al. 1997, 2004, Teillet et al. 2001). Chander et al. (2004) have updated the calibration procedure of Landsat 5 TM data. Ponzoni et al. (2004) have also presented new absolute calibration coefficients for Landsat 5 TM using the Salar de Uyuni as a test site. The access of that knowledge and revised calibration procedures have allowed to convert the Digital Numbers (DN) of the TM images in physical data like radiance or reflectance, which can be related to biophysical and geophysical parameters.

The Brazilian remote sensing user's community (including several scientific agencies and universities) has explored that relationship since the beginning of the nineties using TM as the main source of data. So, it will be quite encouraging if the same could be done with CBERS-2 images, mainly with the CCD data, since the data between the two sensors are quite similar as can be observed in Table II.

Since the launch of CBERS-2 users have asked information about how to convert the DN to physical data. This conversion could be performed using the pre-launch sensors calibration or by the internal calibration procedure specific for each sensor, but due the lack of reliable pre-launch data it was decided to carry out in-flight absolute calibration of the CBERS-2 sensors data using the reflectance-based method at least to allow the mentioned conversion rather than the evaluation of the sensors themselves.

This paper describes the complete procedure to calculate the in-flight absolute calibration coefficients for CBERS-2 CCD images using a reference surface located in the north-east region of Brazil to allow the conversion of the DN to physical values.

\section{MATERIALS AND METHODS}

\section{THe REFERENCE SURface}

There are no ideal calibration sites in Brazil, few sites were identified in the west part of the State of Bahia (northeast region of Brazil) that have the following positive characteristics:

1. The region presents lower cloud cover indices during winter time;

2. The altitude is about $850 \mathrm{~m}$ over the sea level;

3. Sand is the dominant soil (relative high reflectance);

4. During the winter time, large areas of economical crops are prepared to plant and they present enough dimensions for CBERS-2 sensors calibration proposes;

5. The agricultural schedule that is followed every year makes possible to find a specific calibration site with the same characteristics at a specific time of year; 
TABLE II

Comparison between Landsat 5 TM, Landsat 7 ETM+ and CBERS-2 CCD spectral range-spatial resolution.

\begin{tabular}{c|c|c|c}
\hline Band & Landsat 5 TM & Landsat 7 ETM+ & CBERS-2 CCD \\
\hline 1 & $0.450-0.520(30 \mathrm{~m})$ & $0.450-0.515(30 \mathrm{~m})$ & $0.45-0.52(20 \mathrm{~m})$ \\
\hline 2 & $0.520-0.600(30 \mathrm{~m})$ & $0.525-0.605(30 \mathrm{~m})$ & $0.52-0.59(20 \mathrm{~m})$ \\
\hline 3 & $0.630-0.690(30 \mathrm{~m})$ & $0.630-0.690(30 \mathrm{~m})$ & $0.63-0.69(20 \mathrm{~m})$ \\
\hline 4 & $0.760-0.900(30 \mathrm{~m})$ & $0.775-0.900(30 \mathrm{~m})$ & $0.77-0.89(20 \mathrm{~m})$ \\
\hline 5 & $1.550-1.750(30 \mathrm{~m})$ & $1.550-1.750(30 \mathrm{~m})$ & \\
\hline 6 & $10.40-12.50(120 \mathrm{~m})$ & $10.40-12.50(60 \mathrm{~m})$ & \\
\hline 7 & $2.080-2.350(30 \mathrm{~m})$ & $2.090-2.350(30 \mathrm{~m})$ & \\
\hline Pan & & $0.520-0.900(30)$ & $0.51-0.73(20 \mathrm{~m})$ \\
\hline
\end{tabular}

6. The reference surfaces present enough isotropy during the calibration time;

7. The spectral/spatial uniformity is about $6-8 \%$;

8. The region is one of the most arid region of the Brazilian territory;

9. As the reference surfaces are located within farms, there are a lot of roads, thus the access is very easy.

For the reference surface (test site) selection only surfaces covered with bare soil were considered. The spectral characterization of the test site included the spectral homogeneity and the isotropy evaluation according to the procedures adopted by Lamparelli et al. (2003).

\section{Calibration CoefFicients Determination}

\section{Field data}

The selected reference surface was located in Santo Antonio farm and the calibration point was defined in latitude $-12^{\circ} 06^{\prime} 46.2^{\prime \prime}$ and longitude $-46^{\circ} 00^{\prime} 51.0^{\prime \prime}$.

The calibration campaign was performed on $16 \mathrm{Au}-$ gust 2004 during which two kinds of radiometric measurements were carried out: (i) BRFs (Bidirectional Reflectance Factors) from the reference surface using the ASD FieldSpec radiometer running from $400 \mathrm{~nm}$ to $2500 \mathrm{~nm}$ (to register the bidirectional radiance from the surface) and a reference panel covered by Spectralon (to allow the irradiance estimation); and (ii) the direct irradiance from the Sun using a CIMEL 317 sunphotometer running in five spectral bands: B1 1.010 to $1.030 \mu \mathrm{m}$; B2 0.860 to $0.880 \mu \mathrm{m}$; B3 0.660 to $0.680 \mu \mathrm{m}$; B4 0.430 to $0.450 \mu \mathrm{m}$ and B5 0.926 to $0.946 \mu \mathrm{m}$, which data were utilized in the atmosphere characterization by using the derived aerosol transmittance ( $\left.\tau_{\text {aer }}\right)$ and the water vapor content $(U W)$ estimations based on the same steps described by Ponzoni et al. (2004) for the in-flight absolute calibration procedure of the Landsat 5 TM sensor.

The first step in both sets of radiometric measurements was the central point definition in the reference surface. This was accomplished by a GPS device with an estimated positioning error of $2 \mathrm{~m}$ taking into account the distance of the borders.

During the CBERS-2 flight over the study area the radiometric measurements (to determine the BRFs) were carried out taking the central point as a cross centre. Forty BRFs values were determined around the central point (ten for each cross axis). Arithmetic averages (one for each spectral band) of these forty BRF values were determined. At the same time, measurements of the direct irradiance were performed every 10 minutes with the sunphotometer CIMEL 317.

Figure 1 shows a CBERS-2 CCD color composition in which is possible to notice the dominant landscape at the calibration test site. The yellow ring indicates the specific reference surface utilized during the calibration campaign of August 2004.

\section{Image data and calibration coefficients determination}

The coordinates of the central point determined in the field were utilized in the identification of a specific pixel (in the images) from which the digital numbers (in each spectral band) were extracted. These digital numbers 


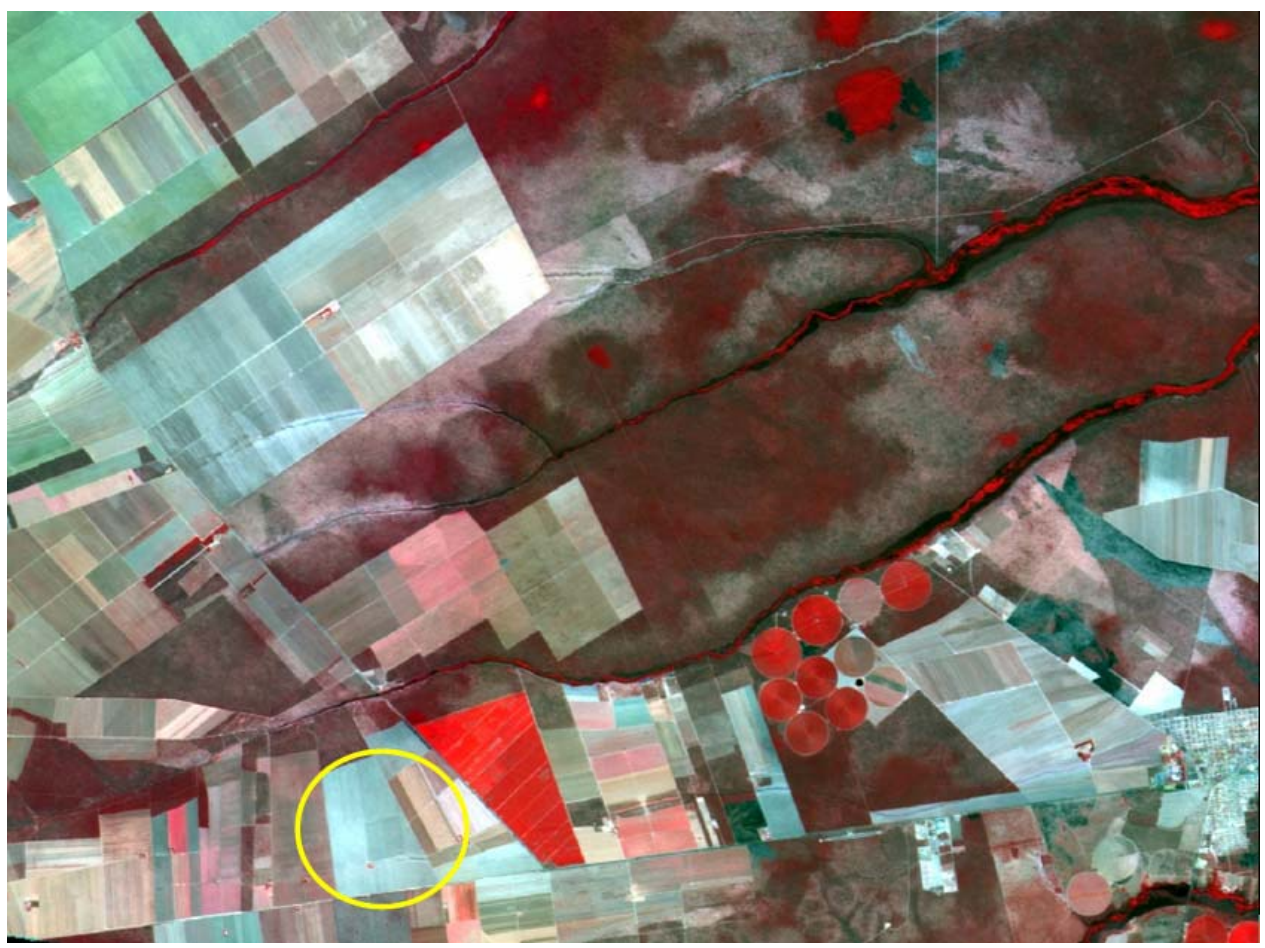

Fig. 1 - CCD-2 (green), CCD-3 (blue) and CCD-4 (red) color composition from the calibration test site. Yellow ring indicates the reference surface.

were then compared with the apparent radiances (in each CCD spectral band) determined from the BRFs collected in the field (average from the forty BRFs measurements) by the $5 \mathrm{~S}$ atmospheric correction code application described by Tanré et al. (1990).

The idea was to calibrate the CCD data at level 2 (relative calibration and geometrically corrected), which is the product that is distributed by INPE to the Brazilian remote sensing users.

CCD images from 16 August 2004 (155/113 orbit/ row CBERS-2 WRS reference) were downloaded from the CBERS-2 catalogue at the INPE's web site and they were georeferenced using the near neighborhood criteria to minimize the georeferencing influence in the $\mathrm{DN}$ values according Ponzoni et al. (2004). The authors have also concluded that there is not significant influence of the georeferencing procedure in the $\mathrm{DN}$ values of the original images.

The determination of calibration coefficients was based on DNs from the central point localized in the CCD images. The relationship between DNs and the apparent radiance calculated from the BRFs values was established by the equation below:

$$
C C_{\lambda}=\frac{D N_{\lambda}}{L_{a p a_{\lambda}}}
$$

where: $C C_{\lambda}$ is the Calibration Coefficient for $\mathrm{CCD}$ spectral band $\lambda(\lambda=1,2,3,4$ and 5);

$D N_{\lambda}$ is the digital number from the CCD images in spectral band $\lambda(\lambda=1,2,3,4$ and 5$)$;

$L_{\text {apa }}$ is the apparent at-sensor radiance determined from the BRF in CCD spectral band $\lambda(\lambda=1,2,3,4$ and 5) given by $\mathrm{W} \cdot \mathrm{m}^{-2} \cdot \mathrm{sr}^{-1} \cdot \mu \mathrm{m}^{-1}$.

\section{Calibration coefficients}

The main objective of the calibration coefficients was the conversion of the DN to apparent radiance (or apparent reflectance). Therefore the equation 1 can be rewritten as:

$$
L_{\text {apa }}=\frac{D N_{\lambda}}{C C_{\lambda}}
$$

Considering the spectral characterization of objects, the reflectance can be derived from radiance as described by 
equation 3:

$$
\rho_{\text {apa } \lambda}=\frac{\pi \times \frac{D N_{\lambda}}{C C_{\lambda}} \times D^{2}}{\operatorname{Esun}_{\lambda} \times \cos (z e n)}
$$

where: $D=$ Earth-Sun distance in astronomic units (for 08/16/2004, $D=0.97513$ );

$$
\pi=3.1415927
$$

$\operatorname{Esun}_{\lambda}=$ Solar Exoatmospheric Irradiance in the top of the atmosphere in band $\lambda(\lambda=1,2,3,4$ and 5);

$\cos (z e n)=$ cosine of the solar zenith angle at the image acquisition time.

For the preliminary evaluation of the calibration coefficients obtained, equation 3 was applied to the CCD images from 16 August 2004 to convert its digital numbers in apparent BRFs. The same procedure was carried out with the CBERS-2 IRMSS data (also from 16 August 2004), whose calibration coefficients were determined by Ponzoni et al. (2006). The IRMSS and CCD converted data were used to create a unique graph.

IRMSS and CCD images from São José dos Campos region (south-east of Brazil) acquired were the field data collected on September 20, 2004 were also converted to $\mathrm{BRF}$ and a similar graph was created.

The preliminary evaluation included the visual comparison of the graph lines for (i) BRF calculated from the field data (BRF field), (ii) the apparent BRF (direct IRMSS data conversion - BRF apparent) and (iii) the surface BRF (BRF surface) determined from the $5 \mathrm{~S}$ atmospheric correction code.

\section{RESULTS AND DISCUSSION}

\section{REFERENCE SURFACE}

According to Scott et al. (1996), the BRF values higher than 0.3 in the entire spectral range were preferred. The selected reference surface did not present BRF $>0.3$ in the visible region, in spite choosing a brighter surface. Teillet et al. (2001) have presented reflectance spectral curves from the Railroad Valley Playa (spectrally characterized in June 1, 1999) and Niobrara, Nebraska (spectrally characterized in June 2, 1999). The first one presented reflectance higher than 0.3 approximately from $0.50 \mu \mathrm{m}$ to $1.85 \mu \mathrm{m}$ and the second one did not present reflectance higher than that value in almost all the spectral range considered (from $0.30 \mu \mathrm{m}$ to $2.50 \mu \mathrm{m}$ ). In spite of that, data from Niobrara test site have been considered in several vicarious calibration campaigns.

Thome et al. (2004) have compared results from different teams that have collected data in these two different test sites for updating the TM/Landsat-5 and ETM+/ Landsat-7 absolute calibration coefficients. They concluded that the differences in the results from the two test sites were about $3 \%$ to $5 \%$, depending upon spectral band and experience of the personal involved. The authors did not conclude that a darker reference surface as Niobrara is unqualified for calibration purposes. Based on these experiences it was decided to carry out the CBERS-2 CCD data calibration campaign.

Considering the spatial homogeneity, averaged Coefficient of Variation of the spectral measurements were $10.9 \%$ (CCD_1), 11.4\% (CCD_2), 11.4\% (CCD_3), $10.2 \%$ (CCD_4) and 9.3\% (CCD_5), indicating that the surface is not enough radiometrically homogeneous as suggested by Scott et al. (1996) (Coefficient of Variation lower than 5\%). For the reference surface isotropy evaluation no tendency was identified in spite of having changes in the illumination geometry during approximately the 2 hours of radiometric measurements in the field.

\section{CALIBRATION COEFFICIENTS}

The BRFs determined in the field were used with the $5 \mathrm{~S}$ atmospheric correction code resulting in apparent radiances that were utilized in the calibration coefficients determination.

The geometric illumination conditions and the atmospheric data estimated from the $5 \mathrm{~S}$ atmospheric correction code are presented in Table III.

Table IV summarizes the radiometric data from the reference surface and from the atmosphere in each CCD spectral band, the digital counts at the central point (from the images) and the calibration coefficients determined.

The preliminary evaluation of these calibration coefficients (CC) included the comparison with coefficients determined during pre-launch calibration tasks performed in laboratory and described by Zhang et al. (2001). Table V presents the pre-launch and the calibration coefficients calculated.

It is important to emphasize that the pre-launch calibration coefficients were determined exclusively from 
TABLE III

Geometric illumination conditions and the atmospheric data estimated from the $5 \mathrm{~S}$ atmospheric correction code.

\begin{tabular}{l|l}
\hline Geometric conditions & \\
\hline Date & 16 August 2004 \\
\hline Universal time $-\mathrm{H}$ & 13.72 \\
\hline Solar zenith angle $-\theta_{\text {sun }}$ & $44.45^{\circ}$ \\
\hline Solar azimuth angle $-\varphi_{\text {sun }}$ & $54.19^{\circ}$ \\
\hline View zenith angle $-\theta_{\text {sat }}$ & $0.00^{\circ}$ \\
\hline View azimuth angle $-\varphi_{\text {sat }}$ & $0.00^{\circ}$ \\
\hline Atmospheric code data & \\
\hline Water content $-\mathrm{U}_{w}$ & $2.440 \mathrm{~g} / \mathrm{cm}^{2}$ \\
\hline Ozone content $-\mathrm{U}_{O z}$ & 248 Dobson \\
\hline Aerosol type & Continental \\
\hline
\end{tabular}

laboratory data (no images). Those calculated in $16^{\text {th }}$ August 2004 were based on images that were submitted to the relative calibration.

Another comparison was made between the calibration coefficients determined by Chinese researchers that carried out similar calibration campaigns in the Gobi desert (China) almost at the same time the Brazilian campaigns were performed. The Chinese results are presented on Table VI.

The calibration coefficients calculated in China were based also on images in which the relative calibration was applied, but there are differences between the procedures adopted in Brazil and in China to generate these images. These differences are explained by different criteria in the gain and bias definitions. The percentage values presented on Table VI represent the relative differences between the calibration coefficients determined in Brazil and those determined in China.

In Figure 2 the differences between the BRF curve acquired in the field (BRF field) and the apparent BRF (BRF app) were coherent considering the scattering phenomena in the visible region and the absorption in the infrared region. The surface BRF (BRF sur) calculated from the $5 \mathrm{~S}$ atmospheric correction code presented similar values to the BRF field, indicating that both the calibration coefficients and the atmospheric characterization were satisfactory.

The application of the calibration coefficients in the images allowed the spectral characterization of the selected targets.

\section{CONCLUSIONS}

The conversion of the DN to BRF values for CCD level 2 data has helped to spectrally characterize objects considering the spectral range of all CBERS-2 sensors. Calibration coefficients are now also available for the CBERS-2 CCD data users. However, it is suggested that additional validation tests, including correlation analysis of field and image-derived radiometric data, have to be carried out.

Different approaches using vegetation, soil, minerals geology and chemical quality of water data have also to be considered in future validation tasks.

\section{ACKNOWLEDGMENTS}

The authors are grateful to the Fundação de Amparo à Pesquisa do Estado de São Paulo (FAPESP) for the financial support; to the graduate students from Faculdade de Engenharia Agrícola of the Universidade Estadual de Campinas (FEAGRI/UNICAMP), Mr. Júlio César Dalla Mora Esquerdo, Mrs. Gláucia Ramirez and Mrs. Liane Weber; to Dr. Marina de Fátima Vilela from the Centro de Pesquisas do Cerrado, Empresa Brasileira de Pesquisa Agropecuária (CPAC/EMBRAPA) and to Dr. Angélica Giarolla, from the Centro de Previsão do Tempo e Estudos Climáticos, Instituto Nacional de Pesquisas Espaciais (CPTEC/INPE), for important help during field work and for intellectual contributions.

\section{RESUMO}

Desde o início da distribuição de imagens dos sensores do satélite CBERS-2 (China-Brazil Earth Resources Satellite) por parte do Instituto Nacional de Pesquisas Espaciais (INPE), a comunidade de usuários solicitava informação sobre a conversão dos números digitais em valores físicos (radiância ou reflectância). Este artigo descreve os principais passos adotados no cálculo dos coeficientes de calibração absoluta para as imagens disponibilizadas no nível 2 de correção (correções radiométrica e geométrica) da câmera CBERS-2 CCD, considerando o método baseado na reflectância de uma superfície de referência. São apresentados também alguns resultados da avaliação preliminar da aplicação desses coeficientes na conversão mencionada.

Palavras-chave: calibração absoluta, CBERS-2, CCD, reflectância. 
TABLE IV

Radiometric data from the reference surface and from the atmosphere in each IRMSS spectral band, the digital counts at the central point and the calibration coefficients determined.

\begin{tabular}{l|c|c|c|c|c}
\hline CCD spectral bands & CCD_1 & CCD_2 & CCD_3 & CCD_4 & CCD_Pan \\
\hline$(\mu \mathrm{m})$ & 0.450 & 0.520 & 0.630 & 0.770 & 0.510 \\
\hline$(\mu \mathrm{m})$ & 0.520 & 0.590 & 0.690 & 0.890 & 0.730 \\
\hline Gas total transmittance $-\mathrm{t}_{g}$ & 0.984 & 0.935 & 0.940 & 0.921 & 0.927 \\
\hline Top of the atmosphere Irradiance $\left(\mathrm{W} / \mathrm{m}^{2} / \mu \mathrm{m}\right)$ & 1934.03 & 1787.10 & 1548.97 & 1069.21 & 1664.33 \\
\hline Surface Irradiance $\left(\mathrm{W} / \mathrm{m}^{2} / \mu \mathrm{m}\right)$ & 1215.29 & 1145.90 & 1021.67 & 702.97 & 1068.06 \\
\hline Surface Reflectance $-\rho$ & 0.118 & 0.168 & 0.226 & 0.298 & 0.204 \\
\hline Apparent Reflectance $-\rho_{a p a}$ & 0.160 & 0.175 & 0.219 & 0.275 & 0.201 \\
\hline Apparent Radiance $-\mathrm{L}_{a p a}\left(\mathrm{~W} / \mathrm{m}^{2} / \mathrm{sr} / \mu \mathrm{m}\right)$ & 70.34 & 70.97 & 77.11 & 66.77 & 76.18 \\
\hline Digital number in the central point $-\mathrm{ND}_{c p}$ & 71 & 137 & 89 & 142 & 112 \\
\hline Calibration coefficients $-\mathrm{CC}$ & $\mathbf{1 . 0 0 9}$ & $\mathbf{1 . 9 3 0}$ & $\mathbf{1 . 1 5 4}$ & $\mathbf{2 . 1 2 7}$ & $\mathbf{1 . 4 8 3}$ \\
\hline
\end{tabular}

TABLE V

Comparison of the calibration coefficients calculated from pre-launch and the vicarious calibration campaign.

\begin{tabular}{c|c|c|c|c|c}
\hline & CCD_1 & CCD_2 & CCD_3 & CCD_4 & CCD_Pan \\
\hline Pre-launch & 0.98 & 1.59 & 1.20 & 2.29 & 1.25 \\
\hline 16th August 2004 & 1.009 & 1.930 & 1.154 & 2.127 & 1.483 \\
\hline
\end{tabular}

TABLE VI

Calibration coefficients determined by Chinese researchers from the Gobi desert (China).

\begin{tabular}{c|c|c|c|c}
\hline & CCD_1 & CCD_2 & CCD_3 & CCD_4 \\
\hline 19th August 2004 & $0.9917(1.72 \%)$ & $1.6761(13.16 \%)$ & $1.0096(12.51 \%)$ & $2.0613(3.09 \%)$ \\
\hline 25th Augus 2004t & $1.0292(-2.00 \%)$ & $1.7254(10.60 \%)$ & $1.0356(10.26 \%)$ & $2.1515(-1.15 \%)$ \\
\hline
\end{tabular}

Obs.: The calibration coefficients for band 5 were not presented.

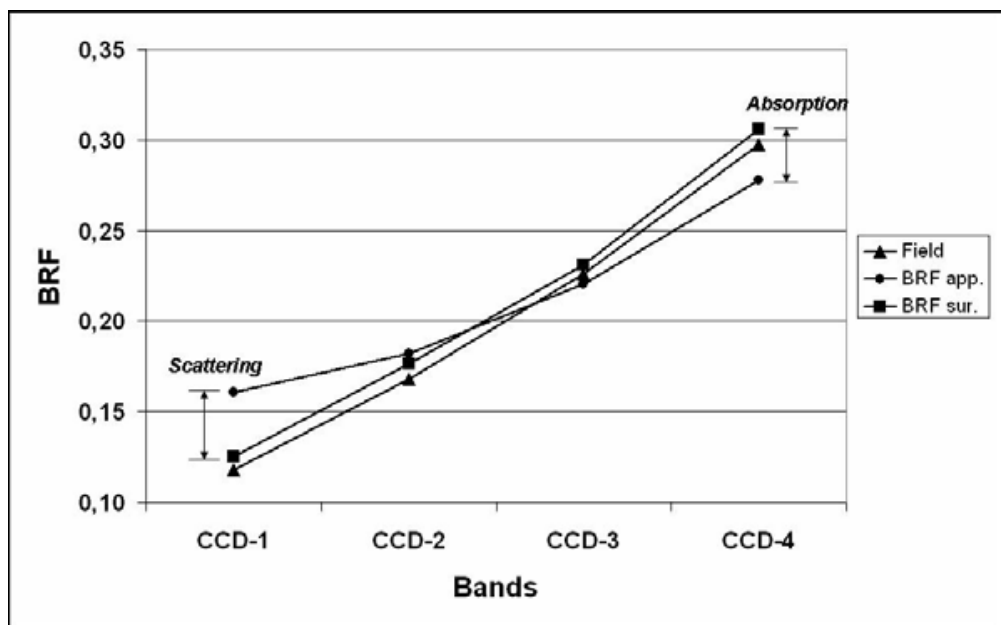

Fig. 2 - Spectral characterization of the reference surface 2 resulted from field data (Field), apparent BRF (BRF app.) and surface BRF (BRF sur.). 


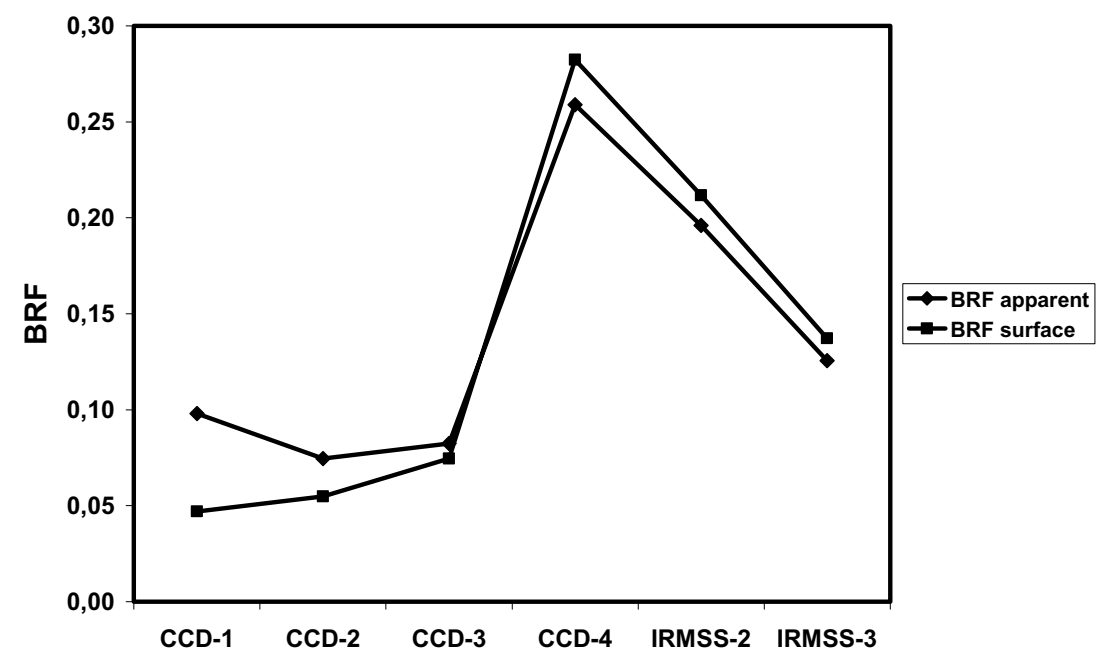

Fig. 3 - BRF data from a seasonal forest (in São José dos Campos region) extracted from the IRMSS and CCD images (20 September 2004).

\section{REFERENCES}

Chander G, Helder Dl, Markham B, Dewald JD, Thome KJ, MiciJevic E And Ruggles A. 2004. Landsat 5 TM reflective-band absolute radiometric calibration. IEEE Trans Geosc Rem Sen 42: 2747-2760.

Lamparelli RAC, Ponzoni FJ, Pellegrino GQ, ZULLO JRJ AND ARNAUd Y. 2003. Spectral characterization of the "Salar de Uyuni" (Bolívia) for orbital optic sensors calibration proposes. IEEE Trans Geos Rem Sen 41: $1461-1468$.

Ponzoni FJ, Zullo JRJ, LAmparelli RAC, PelLEGRINO GQ AND ARNAUD Y. 2004. In-flight absolute calibration of the Landsat $5 \mathrm{TM}$ on the test site Salar de Uyuni. IEEE Trans Geosc Rem Sen 42: 2761-2766.

PONZONI FJ, ZULlo JRJ AND LAMPARELLI RAC. 2006. In-flight absolute calibration of the CBERS-2 IRMSS sensor data. Int J Rem Sen 27: 799-804.

Scott KP, Thome KJ And Brownlee MR. 1996. Evaluation of the Railroad Valley Playa for use in vicarious calibration. Proc SPIE Conf, 2818 p.

Slater PN, Biggar SF, Holm RG, JaCKSON RD, MaO Y, Moran MS, Palmer JM AND Yuan B. 1987. Reflectance- and Radiance-Based Methods for the In-Flight Absolute Calibration of Multispectral Sensors. Rem Sen Environ 22: 11-37.
TAnré D, Deroo C, Duhaut P, Herman M And MorCRETTE JJ. 1990. Description of a computer code to simulate the satellite signal in the solar spectrum: the $5 \mathrm{~S}$ code. Int J Rem Sen 11: 659-668.

Teillet PM, BARKer BL, MARKham RR, Irish G, FEDOSEJEVS JC AND STOREY JC. 2001. Radiometric cross-calibration of the Landsat-7 ETM+ and Landsat-5 TM sensors based on tandem data sets. Rem Sen Environ 78: $39-54$.

Thome KJ, Markham B, Barker J, Slater P And BIGGAR S. 1997. Radiometric Calibration of Landsat. Photog Eng Rem Sen 63: 853-858.

Thome KJ, Helder DL, Aaron D And Dewald JD. 2004. Landsat-5 TM and Landsat-7 ETM+ absolute radiometric calibration using the reflectance-based method. IEEE Trans Geosc Rem Sen 42: 2777-2785.

Zhang Y, Chen S, Zhu M, Zhou S and Wu Y. 2001. Preflight calibration of HY-1 Satellite 4-Band CCD Camera. In: Sec Asian Conf Rem Sen, Singapure, 5-9 November. 